\title{
Model of Flexible Periodic Vehicle Routing Problem-Service Choice Considering Inventory Status
}

\author{
Muhammad Alde Rizal a*, Ifa Saidatuningtyas b \\ a Politeknik Negeri APP Jakarta, Indonesia \\ Jl. Timbul No.34, Cipedak, Jakarta, Indonesia \\ b Politeknik Pos Indonesia, Indonesia \\ Jl. Sarijadi No.54, Bandung, West Java, Indonesia \\ Correspondence author: alderizal29@gmail.com
}

\section{ARTICLE INFO}

Article history

Received November 16, 2020

Revised February 24, 2021

Accepted February 27, 2021

Available Online February 28, 2021

Keywords

Vehicle route

Flexible Periodic

Branch-and-bound

Inventory

PVRP

\begin{abstract}
Vehicle routing problems and inventory problems need to be integrated in order to improve performance. This research discusses the determination of vehicle routes for product delivery with periodic delivery times that are released at any time depending on the inventory status. A mixed-integer linear programming model in determining periodic flexible visiting vehicles' route considering inventory is proposed to solve this problem. This model also accommodates time window constraints, retailer warehouse capacity. The search for solutions was carried out using the branch-and-bound method with the help of Lingo 18.0. The mathematical model testing result saves shipping costs and inventory costs. In addition, the developing mathematical model offers the flexibility of visiting depending on the inventory status of the consumer. The sensitivity analysis of the model results in the vehicle capacity influence the total cost and routes formed.
\end{abstract}

\section{Introduction}

The most popular combinatorial optimization problem is the Vehicle Routing Problem (VRP) [1]. VRP was first introduced in 1959 [2]. VRP is considered popular because it can solve companies' problems related to product delivery and pick-up [1]. VRP is a complex problem with various characteristics that allow for development. Some researchers have conducted a taxonomic review of VRP development [3][4]. The development of VRP research includes problems with heterogeneous fleets, time windows, split delivery, and pick-up and delivery problems. Some of the best known VRP developments are the Vehicle Routing Problem with pick-ups and delivery (VRPPD) [5], [6], [7]; Vehicle Routing Problem with split delivery (SDVRP) [8], [9]; Vehicle Routing Problem with time window (VRPTW) [10],[11],[12],[13],[14]. Besides the VRP types above, there are several other types of VRP developments such as the Periodic Vehicle Routing Problem (PVRP), Multi Depot Vehicle Routing Problem (MDVRP), Capacitated Vehicle Routing Problem (CVRP), Green Vehicle Routing Problem (G-VRP). 
VRP is useful for finding a sequence of visits that has a minimum cost [3]. PVRP is one of the developments of VRP, which also generates routes. The mathematical model formulation of the Periodic Vehicle Routing Problem (PVRP) was first introduced in 1979 as the Assignment Routing Problem [15]. Each node is not visited every day, but a minimum number of visits is determined. The study was then developed, taking into account the visiting days at each node [16]. After that, research related to PVRP overgrew. PVRP has been used to research many types of products. It shows that, indeed, problems with these characteristics occur in everyday life. Several types of items used as inspiration in PVRP research include distribution of vegetables [17], waste collection [15] and [18], utility services [19], distribution of auto parts [20], home health care (HCC) logistics [21], beverage distribution in beverage machines [22], and many others. Apart from the types of products, much PVRP research has also been developed towards finding solutions with heuristic methods. The heuristic method is a method that is built based on experience or judgment to produce a reasonable solution to a problem but cannot be guaranteed to get an optimal solution [23]. One reason for finding a solution using heuristics is finding a solution when the number of consumers served is large. A search of PVRP heuristic solution has been done by some researchers, like using variable neigborhood search [24], neigborhood search [25], hybrid genetic algorithm [26], particle swarm [27], hybridization of tabu search [21], large adaptive neighborhood [28], and hybrid metaheuristic algorithm [29].

Research related to PVRP has undergone many developments. PVRP is categorized into three main categories, namely multi-depot PVRP (MDPVRP), PVRP with time windows (PVRPTW), and PVRP with service choice (PVRP-SC) [30]. Multi depot PVRP can be seen in studies [19] and [31]. PVRP with time windows can be understood in studies [24], [25], [31], [32], and [33]. Meanwhile, what is meant by PVRP-SC is PVRP which makes the frequency of visits a decision variable in finding solutions as in research [34]. PVRP-SC is said to have proximity characteristics to the Inventory Routing Problem (IRP). The proximity characteristics between PVRP-SC and IRP, among others, determine the frequency of visits, route configuration, and the number of deliveries [30]. The PVRPSC characteristics combination and the number of products delivered to the node are determined by the node's schedule. The IRP problem's characteristic is that the number delivered at the node is a decision variable that differs from the frequency of visits [34]. The development of this problem [34], by adding the flexible characteristics of FPVRP, was carried out by [32]. What is meant by flexibility is to make the schedule of visits and quantity limits flexible.

Research developed by Archetti, et al. [32] provided a new perspective for modeling by considering flexibility. One study that considered flexibility is the heuristic procedure performed by [35]. Archetti, et al. [32] continued their research by finding a FPVRP algorithm solution in two stages. The first stage was to develop all possible initial solutions then followed by tabu search [36]. Several further developments were related to the twoechelon distribution channel with flexibility in service time [37]. In addition, a model was also developed, taking into account the discount on the consumer, which provides flexibility in the delivery time [38]. Furthermore, the development of a joint optimization strategy model between inventories was also proposed.

Based on the literature study that has been conducted, the FPVRP problem is quite investigated in number. Unfortunately, no research considers the limits of consumer inventory capacity and consumer inventory status. This study tries to develop a model proposed by Archetti, et al. [32]. The previous model has a periodic characteristic of demand without considering the inventory status, capacity limitations, and customer visit periods. In addition, the previous model assumes the demand for each period is the same, 
and does not consider the time windows. From the Archetti, et al. [32] model, there are still gaps in the development that can be done. This study develops the Archetti, et al. [32] model by adding a time window, the periodic request, and the consumer's inventory status. The main difference is in the flexible nature of customer visits. In this study, the number of consumer visits is flexible, not limited, and not determined, but is influenced by the consumer's inventory status. To the authors' knowledge, this study is the first to discuss the Flexible Periodic Vehicle Routing Problem-Service Choice Considering Inventory Status. Therefore, this study aims to develop a Flexible Periodic Vehicle Routing ProblemService Choice Considering Inventory Status (FPVRP-SCI) model. This research contributes to the PVRP field by proposing a model for the FPVRP-SCI problem.

The model developed in this study is Mixed Integer Linear Programming (MILP) with a branch-and-bound method of solving. Branch-and-bound is a method commonly used to solve complex combination problems [39]. The branch-and-bound method tries to connect each customer in the form of a branch with a certain sequence of visits (route of visits) [40]. The branch-and-bound main idea is to break the solution space in succession into specific subsets (branches) [39]. The branches are removed one by one when a solution is obtained that minimizes the objective function. In general, Lingo 18.0 combines each consumer into a visiting route, taking into account limitations, resulting in a minimum objective function.

The paper is presented as follows: methods are presented in section 2 . The results of problem optimization, validation of inventory status, and sensitivity analysis are presented in section 3 . The final section presents conclusions and further work.

\section{Methods}

In the method section, this study was divided into four sub-sections, namely (1) determining assumptions, notation, and developing mathematical models, (2) data and experiments, (3) model validation using DRP, and (4) sensitivity analysis of the developed model.

\subsection{Assumptions, Notations, and Mathematical Models}

Some of the assumptions used in this problem are: (1) delivery of products to customers in the form of delivery for a single product, (2) the problem of using a single depot for delivery to customers, (3) the depot serves customer requests during the planning horizon, (4) each customer has a certain time window, (5) the vehicle used has a certain capacity, (6) each customer needs service time when the delivery is executed, and (7) each vehicle assigned to each route departs and returns to the warehouse.

Research considers demand over the planning horizon. In addition, this study has a decision variable of the maximum number of shipping lots for each customer. Furthermore, the vehicle visits to customers minimize the total cost, including distribution costs and inventory costs.

The parameters in the mathematical model on the FPVRP-SCI problem are denoted as follows:
$i, j$
$T$
: Node index (depot and consumer)
$N$
: Period index (day)
: Set of depots and consumers $\{0$ represents the depot and $1,2,3 \ldots \mathrm{n}$ represents consumers $\}$
$N_{c} \quad$ : Set of consumers $\{1,2,3,4, \ldots, \mathrm{n}\}$
$T \quad$ : Set of planning periods (days) $\{1,2, \ldots, \mathrm{t}\}$
$D_{i} \quad$ : The demand of delivery to consumers per period (unit) 


\begin{tabular}{|c|c|c|}
\hline \multirow{2}{*}{\multicolumn{2}{|c|}{$\begin{array}{c}w_{i} \\
O\end{array}$}} & : Consumer warehouse capacity (unit) \\
\hline & & : Vehicle capacity (unit) \\
\hline \multicolumn{2}{|c|}{$c_{i j}$} & : Travel time from location i to location $\mathrm{j}$ (minutes) \\
\hline \multicolumn{2}{|l|}{$s_{i}$} & : Duration of service for each customer (hours) \\
\hline \multicolumn{2}{|l|}{$H$} & : Maximum travel time on one tour (minutes) \\
\hline \multicolumn{2}{|l|}{$M$} & : The number constant is huge \\
\hline \multicolumn{2}{|l|}{$e_{i}$} & : Open time per consumer (minutes) \\
\hline \multicolumn{2}{|l|}{$l_{i}$} & : Closing time for each consumer (minutes) \\
\hline \multicolumn{2}{|l|}{$f c$} & : Fixed costs if one vehicle is used (rupiahs/unit) \\
\hline \multicolumn{2}{|l|}{$v c$} & : Variable costs based on vehicle trips (rupiahs/minute) \\
\hline \multicolumn{2}{|l|}{$h$} & : Cost of storing unused products per unit (rupiahs/unit) \\
\hline \multicolumn{2}{|l|}{$I e_{i}$} & : Inventory condition at the beginning of the period (units) \\
\hline \multicolumn{2}{|l|}{$I l_{i}$} & : Inventory condition at the end of the period (units) \\
\hline \multicolumn{2}{|l|}{$p$} & : Number of periods (days) \\
\hline \multicolumn{2}{|l|}{$v$} & : Vehicle speed (Km/min) \\
\hline \multicolumn{2}{|l|}{$q_{i}^{t}$} & : Delivery quantity to customer i on day t (unit/day) \\
\hline \multicolumn{2}{|c|}{$l e_{i j}^{t}$} & : Delivery cargo from location i to location $\mathrm{j}$ on day $\mathrm{t}$ (unit/day) \\
\hline \multicolumn{2}{|l|}{$l_{i}^{t}$} & : Accumulated delivery cargo at location i on day t (unit/day) \\
\hline \multicolumn{2}{|l|}{$t_{i}^{t}$} & : Accumulated travel time at location i day to $t$ (minutes/day) \\
\hline \multicolumn{2}{|l|}{$I_{i}^{t}$} & : Inventory level of delivery demands per day (units/day) \\
\hline \multirow{3}{*}{$\begin{array}{c}Z \\
x_{i j}^{t}\end{array}$} & & : Total cost of travel (rupiahs) \\
\hline & $\left\{\begin{array}{l}1 \\
0\end{array}\right.$ & the journey from node $\mathrm{i}$ to $\mathrm{j}$ on day $\mathrm{t}$, \\
\hline & & Others \\
\hline \multirow[t]{2}{*}{$y_{i}^{t}$} & $\left\{\begin{array}{l}1 \\
0\end{array}\right.$ & Node $\mathrm{i}$ is visited on day $\mathrm{t}$, \\
\hline & & Others \\
\hline
\end{tabular}

As stated earlier, the MILP model was developed from the model proposed by Archetti, et al. [32]. The MILP model is divided into two main parts, namely the objective function and the limiting function. The following is the MILP model proposed to solve the FPVRP-SCI problem.

Objective Function :

$$
M I N Z=\sum_{t \in T} \sum_{j \in N} f_{c} x_{0 j}^{t}+\sum_{t \in T} \sum_{i \in N} \sum_{i \in N} x_{i j}^{t} c_{i j} v_{c}+\sum_{t \in T} \sum_{i \in N_{c}}\left(I_{i}^{t} h\right)
$$

Subject to :

$$
\begin{aligned}
& I_{i}^{t}=I_{i}^{t-1}-\left(\frac{D_{i}}{p}\right)+q_{i}^{t} ; \forall i \in N_{c}, t \in T \\
& \sum_{t} q_{i}^{t}=D_{i}+\left(I l_{i}-I e_{i}\right) ; \forall i \in N_{c} \\
& q_{i}^{t} \leq w_{i}-I_{i}^{t-1} ; \forall i \in N_{c}, t \in T \\
& I_{i}^{0}=I e_{i} ; \forall i \in N_{c} \\
& I_{i}^{p}=I l_{i} ; \forall i \in N_{c} \\
& \sum_{i \in N_{c}} q_{i}^{t} \leq \sum_{j \in N_{c}} Q x_{0 j}^{t} ; \forall t \in T \\
& l e_{i j}^{t} \leq Q x_{i j}^{t} ; \forall i, j \in N, t \in T
\end{aligned}
$$




$$
\begin{aligned}
& \sum_{j \in N} l e_{j i}^{t}-\sum_{j \in N} l e_{i j}^{t}=q_{i}^{t} ; \forall i \in N_{c}, t \in T \\
& \sum_{i \in N} x_{i j}^{t}=y_{j}^{t} ; \forall t \in T, j \in N_{c} \\
& \sum_{j \in N} x_{i j}^{t}=\sum_{j \in N} x_{j i}^{t} ; \forall i \in N_{c}, t \in T \\
& \sum_{j \in N} x_{i j}^{t} \leq 1 ; \forall t \in T, i \in N_{c} \\
& t_{j}^{t} \geq t_{i}^{t}+s_{i}+v c_{i j}-M\left(1-x_{i j}^{t}\right) ; \forall t \in T, i \in N, j \in N_{c} \\
& t_{i}^{t} \leq H y_{i}^{t} ; \forall i \in N, t \in T \\
& e_{i} y_{i}^{t} \leq t_{i}^{t} \leq\left(l_{i}-s_{i}\right) y_{i}^{t} ; \forall t \in T, i \in N, j \in N_{c} \\
& \left(I_{i}^{t}\right) \geq 0 ; \forall i, j \in N, t \in T \\
& \left(q_{i}^{t}, l e_{i j}^{t}\right) \in\{0,1,2, \ldots . n\} ; \forall i \in N_{c}, t \in T \\
& \left(x_{i j}^{t}, y_{i}^{t}\right) \in\{0,1\} ; \forall i, j \in N, t \in T
\end{aligned}
$$

The objective function (1) states the total cost consisting of inventory costs and transportation costs. Transportation costs consist of fixed costs and variable costs of vehicles. Inventory costs consist of the cost of storing products to consumers. Constraint (2) shows the accumulated changes in inventory for each period. Constraint (3) is a barrier to ensure that customer requests are fulfilled. Equation (4) shows the barrier that ensures the warehouse capacity is met. Constraint (5-6) formulates the initial and end period inventory status for each customer. Constraint (7-8) is a barrier to determine the number of vehicles used per day and vehicle capacity. Constraint (9) shows the load on each consumer. Limiter (10) aims to ensure that the consumer is visited on day t. Constraint (11) describes every vehicle that comes to consumer i must leave that customer i. Constraint (12) formulates that each consumer is visited once a day at maximum. Constraint (13) is the accumulated travel time of the vehicle to node $\mathrm{j}$ on day $\mathrm{t}$ that is the accumulated travel time from node i plus the service time at node i. Constraint (14) is a limitation so that the vehicle travel time does not exceed the maximum vehicle time. Constraint (15) formulates the time window for the consumer. Constructor (16) is a nonnegative limiter for the variable. Constraint (17) represents integer limiter. Constraint (18) is a binary limiter for the decision variable.

\subsection{Data and Experiments}

This problem was studied from problems in actual conditions. This case study was based on the problems that existed in the franchise businesses in Indonesia. The data collected included the data of vehicle capacity $(Q)$ that was 30 units, the maximum travel time on one tour $(H)$ was 1,236 minutes, the constant vehicle speed $(v) 1 \mathrm{~km} /$ minute, the cost of storing unused products per unit $(h)$ 20,000 IDR, variable costs based on vehicle trips $(v c)$ 2,500 IDR, fixed cost if one vehicle was used $(f c) 500,000 \mathrm{IDR}$, and the number of days period used in the $(p)$ calculation was five days. The number of consumers used in data processing was as many as eight consumers. The detailed data can be seen in Table 1 , and the coordinates of the consumer's location can be seen in Table 2. 
Table 1. Data used

\begin{tabular}{lccccccccc}
\multicolumn{1}{c}{$\mathrm{N}$} & Depot & $\mathrm{N} 1$ & $\mathrm{~N} 2$ & $\mathrm{~N} 3$ & $\mathrm{~N} 4$ & $\mathrm{~N} 5$ & $\mathrm{~N} 6$ & $\mathrm{~N} 7$ & $\mathrm{~N} 8$ \\
\hline $\mathrm{s}$ (minutes) & 0 & 10 & 10 & 10 & 10 & 10 & 10 & 10 & 10 \\
\hline $\mathrm{Ie}_{\mathrm{i}}$ (minutes) & 0 & 5 & 0 & 10 & 5 & 5 & 10 & 5 & 5 \\
\hline $\mathrm{Il}_{\mathrm{i}}$ (minutes) & 0 & 10 & 15 & 10 & 15 & 10 & 15 & 10 & 15 \\
\hline $\mathrm{e}_{\mathrm{i}}$ (minutes) & 0 & 912 & 825 & 65 & 727 & 15 & 621 & 170 & 255 \\
\hline $\mathrm{l}_{\mathrm{i}}$ (minutes) & 1236 & 967 & 870 & 146 & 782 & 167 & 702 & 225 & 324 \\
\hline $\mathrm{D}_{\mathrm{i}}$ (units) & 0 & 10 & 20 & 10 & 10 & 10 & 20 & 10 & 20 \\
\hline $\mathrm{W}_{\mathrm{i}}$ (units) & 0 & 30 & 30 & 30 & 30 & 30 & 30 & 30 & 30 \\
\hline
\end{tabular}

Table 2. Consumer location coordinate data

\begin{tabular}{cccccccccc} 
& Depot & N1 & N2 & N3 & N4 & N5 & N6 & N7 & N8 \\
\hline X axis & 0 & 5 & 5 & -7 & 16 & -9 & -15 & 0 & -2 \\
\hline Y axis & 0 & -7 & 20 & -16 & 18 & 15 & 19 & -10 & 18
\end{tabular}

In Table 2 , the depot position is depicted at coordinates $(0,0)$ to facilitate modeling and data processing. The data obtained is then processed into two parts. The first is the determination of the route generated by the model, and the second is the analysis of the demand for the results of the model.

Data processing uses Lingo 18.0 software which runs on Intel Core i5-8400 @ $2.8 \mathrm{GHz}$ and $8 \mathrm{~Gb}$ Ram at one depot (single depot) and eight consumers for five days. Lingo 18.0 looks for the optimal solution taking into account several. The optimal solution in this route-finding case is the one that yields the minimum cost.

\subsection{Result Validation}

To ensure consumers' inventory status, validation of the proposed MILP model results is carried out using distribution requirement planning (DRP) [41]. Regarding the actual system used, the validation is done using DRP.

DRP can be used as a control parameter in inventory, such as safety stock and when inventory is needed [42]. In addition, DRP is an inventory management system that deals with stock replenishment in a multi-echelon distribution system. DRP helps determine when a layer in a particular echelon places orders in the next echelon. DRP can decide when the order is placed and how much the transaction costs [43].

\subsection{Sensitivity Analysis}

Sensitivity analysis is an essential part of building testing and model development. Sensitivity analysis is performed by checking the model's output when input changes are given [44]. In developing this model, a sensitivity test is carried out by changing the number of vehicle capacities. Vehicle capacity is a simple limit that can affect how much cargo is carried and the number of customers that can be visited. Twelve variations of changes in vehicle capacity are in the sensitivity analysis. The changes of vehicle capacity are tested from a value of 20-600. In this sensitivity analysis, vehicle capacity changes are tested to determine the effect of changes in the number of routes and destination functions. 


\section{Results and Discussion}

\subsection{Route Results}

The results of determining the vehicle's route using the lingo software can be seen in Fig. 1, Fig. 2, and Fig. 3. The resulting destination function is 8,713,750 IDR. From data processing, it was obtained the results of sending three times. On the first day. One delivery route is obtained with one vehicle shown in Fig. 1. On the 2nd day, one vehicle route is obtained with one vehicle, which can be seen in Fig. 2. The number of routes generated on the 3rd-day delivery was two routes shown in Fig. 3. The number of vehicles required on the 3 rd day is four vehicles. The first vehicle serves consumers $N_{5}$ and $N_{6}$; second vehicle serves $N_{3}$ and $N_{8}$; the third vehicle serves $N_{7}$ and $N_{2}$; and the last vehicle serves $N_{4}$ and $N_{1}$.

The research results in Fig. 1 - Fig. 3 show that every consumer is not visited every day. In a week, some consumers have been visited once $\left(N_{3}\right)$, consumers who have been visited twice $\left(N_{1}, N_{4}, N_{5}, N_{6}, N_{7}\right)$, and consumers who have been visited three times $\left(N_{2}\right.$ and $\left.N_{8}\right)$. The consumers are visited with periodic delivery times, but free on any day (flexible). Each customer is visited on a different day, depending on the status of the inventory.

\subsection{Solution Validation to Inventory Status}

Solution validation testing related to the resulting inventory status is carried out with DRP. Validation of the state of each consumer's inventory is tested on consumers who are visited once, twice, and three times a week. Inventory status for $N_{1}$, $N_{3}$, and $N_{8}$ consumers are described in more detail in Table 3, Table 4, and Table 5.

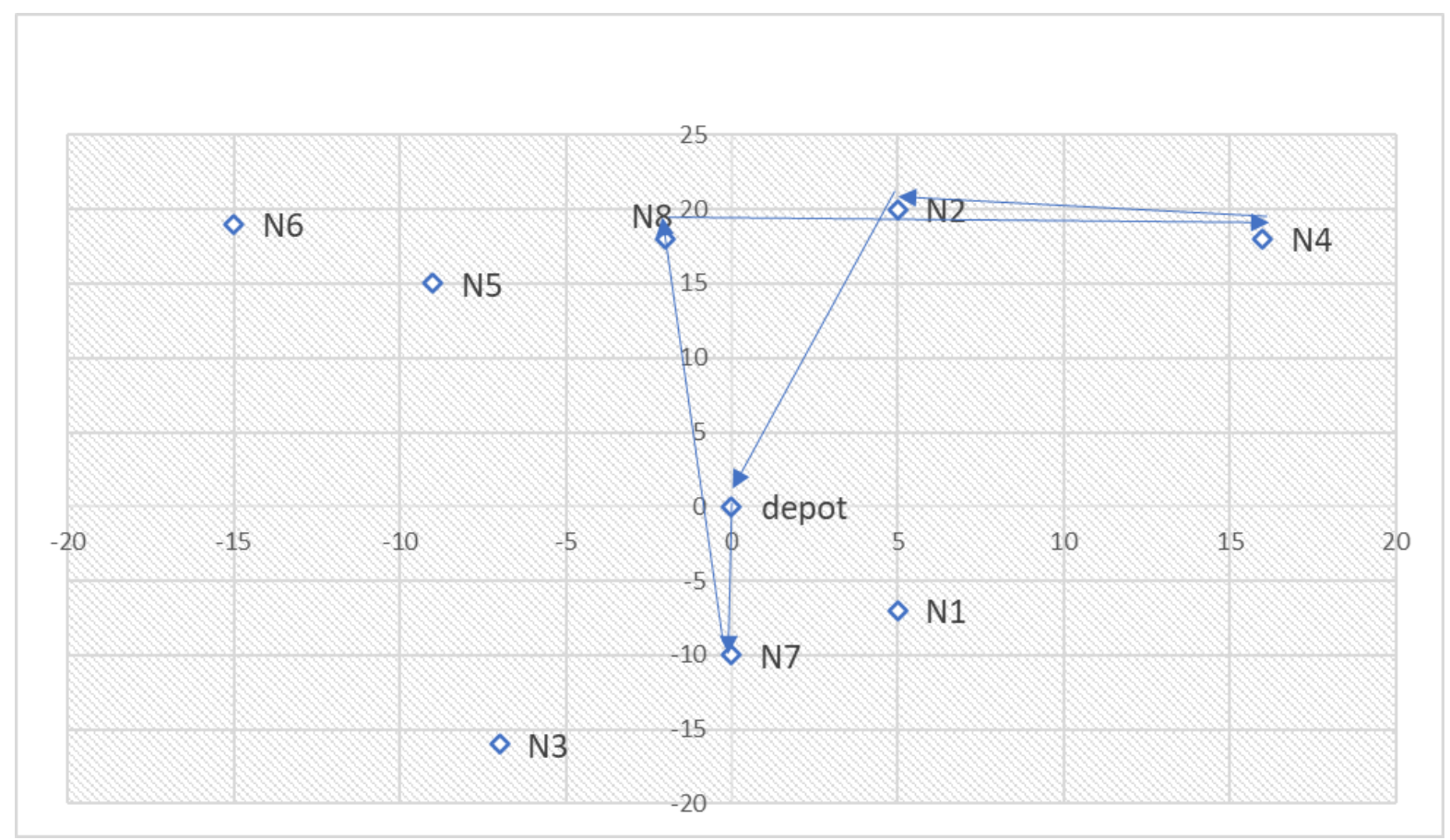

Fig. 1. The route of the vehicle of the first delivery 


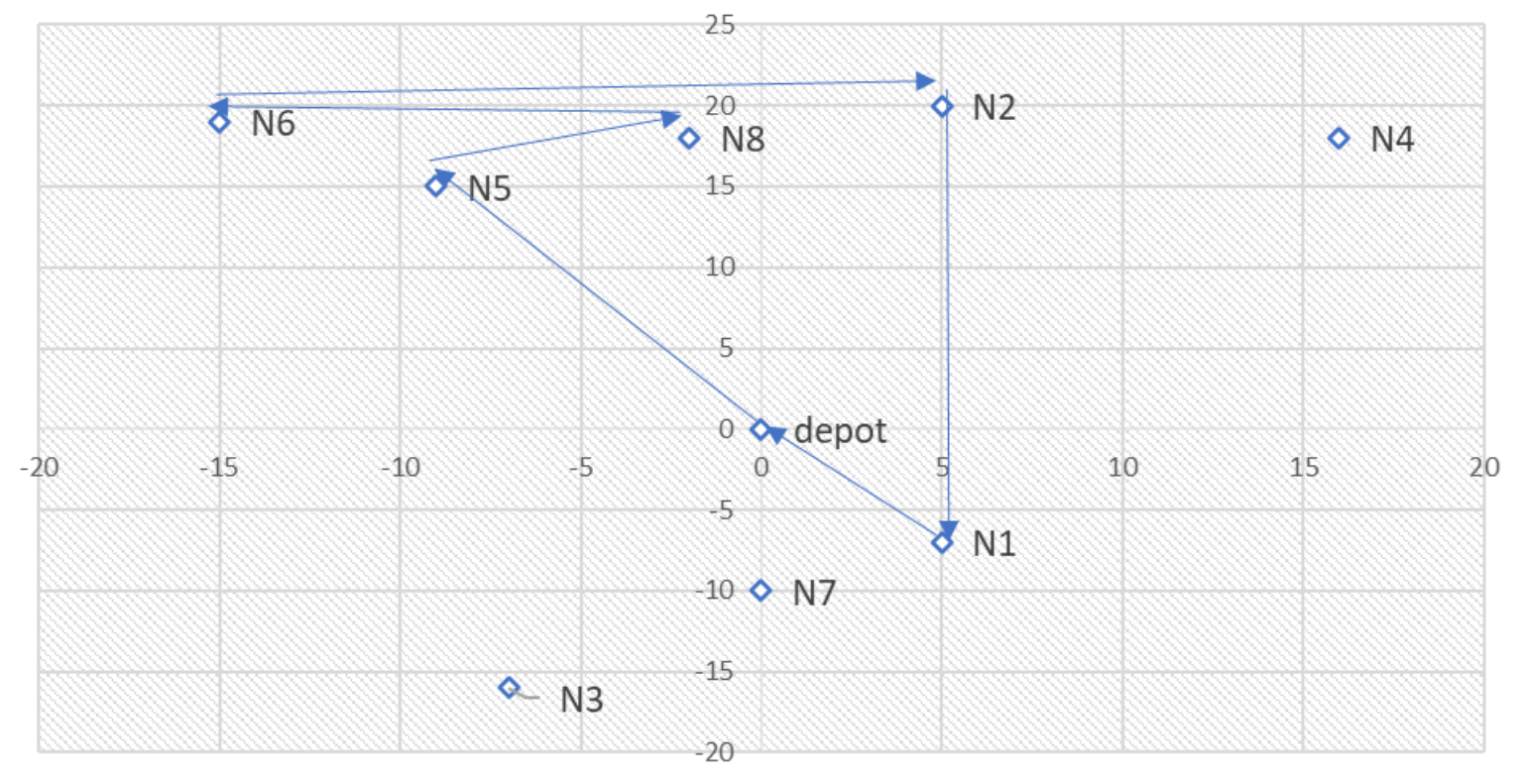

Fig. 2. The route of the vehicle of the second delivery

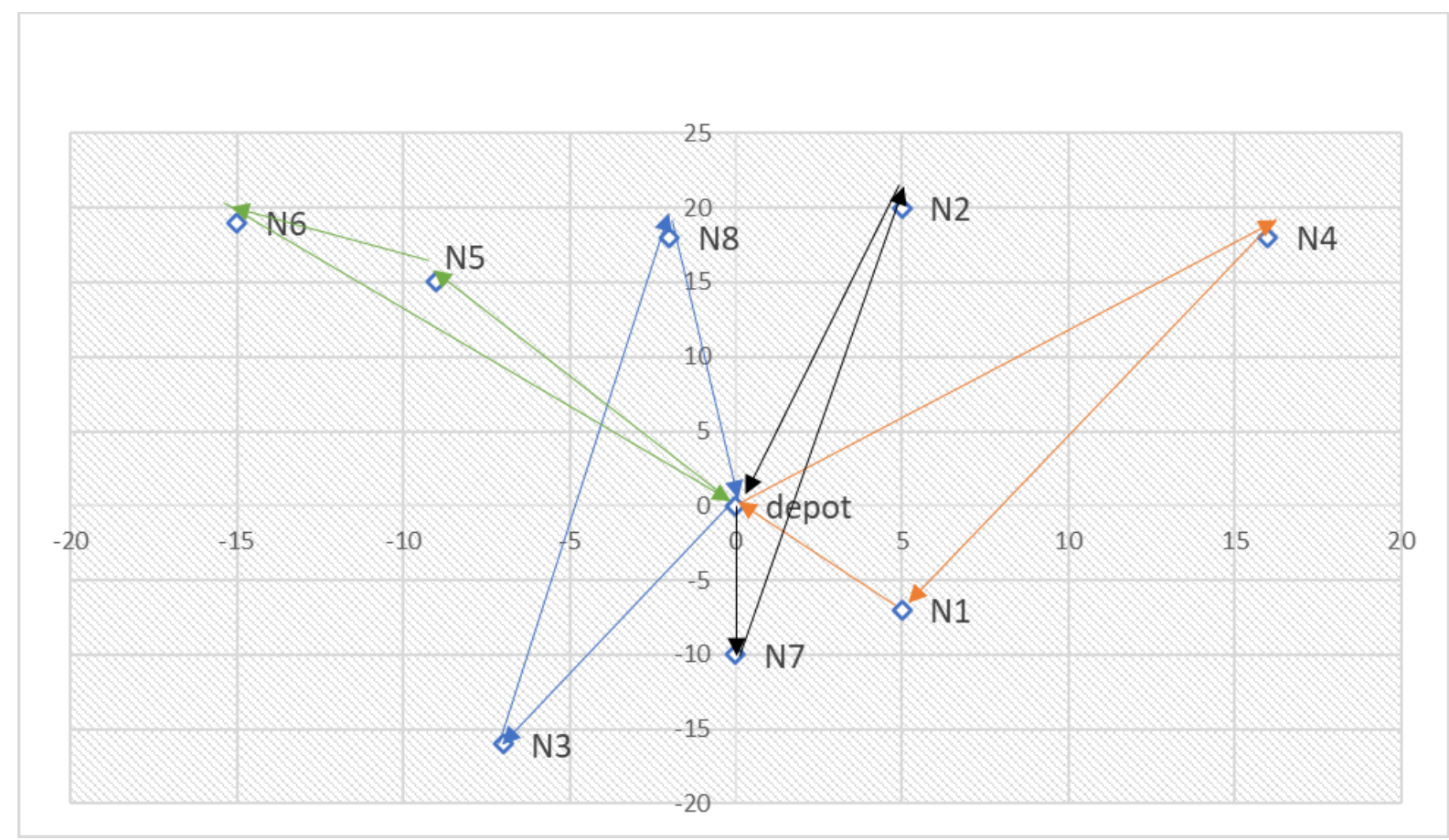

Fig. 3. The route of the vehicle of the third delivery 
Table 3. The validaton of the inventory status of consumers N1

\begin{tabular}{lllllll}
\multicolumn{1}{c}{ Periode } & 0 & 1 & 2 & 3 & 4 & 5 \\
\hline Gross Requirement (GR) & 0 & 2 & 2 & 2 & 2 & 2 \\
Scheduled Receipts (SR) & 0 & 0 & 0 & 3 & 0 & 12 \\
On Hand (OH) & 5 & 3 & 1 & 2 & 0 & 10 \\
Net Requirement (NR) & 0 & 0 & 0 & 1 & 0 & 12 \\
Planned Order Receipts & 0 & 0 & 0 & 3 & 0 & 12 \\
(POR) & & & & &
\end{tabular}

Table 4. The validaton of the inventory status of consumers N3

\begin{tabular}{lcccccc}
\multicolumn{1}{c}{ Periode } & 0 & 1 & 2 & 3 & 4 & 5 \\
\hline Gross Requirement (GR) & 0 & 2 & 2 & 2 & 2 & 2 \\
Scheduled Receipts (SR) & 0 & 0 & 0 & 0 & 0 & 10 \\
On Hand (OH) & 10 & 8 & 6 & 4 & 2 & 10 \\
Net Requirement (NR) & 0 & 0 & 0 & 0 & 0 & 10 \\
Planned Order Receipts (POR) & 0 & 0 & 0 & 0 & 0 & 10 \\
\hline
\end{tabular}

Table 5. The validaton of the inventory status of consumers N8

\begin{tabular}{lllllll}
\multicolumn{1}{c}{ Periode } & 0 & 1 & 2 & 3 & 4 & 5 \\
Gross Requirement (GR) & 0 & 4 & 4 & 4 & 4 & 4 \\
Scheduled Receipts (SR) & 0 & 3 & 0 & 8 & 0 & 19 \\
On Hand (OH) & 5 & 4 & 0 & 4 & 0 & 15 \\
Net Requirement (NR) & 0 & 0 & 0 & 4 & 0 & 19 \\
Planned Order Receipts (POR) & 0 & 3 & 0 & 8 & 0 & 19
\end{tabular}

Validation of each consumer's inventory status is shown in Table 3, Table 4, and Table 5. The table results show that the model developed is valid when viewed from an inventory status perspective. The status of Planned Order Receipts / POR for each consumer is matched with the route formed in Fig. 1 to Fig. 3. In Table 3, the POR status of $N_{1}$ consumer is in the $3 \mathrm{rd}$ and 5 th periods while in the results in sub-chapter $3.1, N_{1}$ consumers are considered to be included in the visit route on the third and fifth days, as seen in Fig. 2 and Fig. 3. $N_{3}$ consumer based on their POR status were visited once, which is on the fifth day of the period that is by the results in Fig. 3 . While $N_{8}$ were visited three times. The results of the DRP prove that the model developed is valid when viewed from the inventory status.

\subsection{Sensitivity Analysis}

The developed model's sensitivity test results by making changes to vehicle capacity can be seen in Table 6 . The effect analysis by changing the vehicle capacity variable was carried out because this periodic flexible study's initial objective was to optimize vehicle capacity. Therefore, the effect of changes in vehicle capacity should not be too large on total costs.

Based on the results of the sensitivity analysis in Table 6, it can be seen that the effect of vehicle capacity on total costs is not significant. It is because the flexible method has optimized the use of vehicle capacity. Thus, changes in vehicle capacity only affect the number of visiting routes. In Table 6 , it is known that there was a change in total costs at 
the beginning. Changes in total costs occur as the number of routes decreases. Furthermore, after the number of routes is not decreased, it can be seen that the total cost tends to remain unchanged.

Table 6 . The results of the sensitivity analysis of changes in vehicle capacity

\begin{tabular}{ccc} 
Vehicle Capacity $(Q)$ & $\begin{array}{c}\text { Total cost (IDR) in } \\
\text { thousands }\end{array}$ & Number route \\
20 & 10060.75 & 9 \\
30 & 8713.75 & 6 \\
40 & 7952.75 & 5 \\
50 & 7760.75 & 5 \\
60 & 7298.25 & 4 \\
70 & 7282.5 & 4 \\
80 & 7277.75 & 4 \\
90 & 7217.5 & 4 \\
100 & 7217.5 & 4 \\
115 & 7004.25 & 3 \\
125 & 6804.25 & 3 \\
150 & 6804.25 & 3 \\
300 & 6804.25 & 3 \\
600 & 6804.25 & 3 \\
\hline
\end{tabular}

\section{Conclusion}

The developed MILP model has succeeded in achieving the expected goals. Based on the model trial, it was found that each consumer was not visited every day but was periodically and flexible. From the research results, it was found that there were consumers who were only visited once $\left(N_{3}\right)$ and $\left(N_{3}\right)$. Some consumers were visited twice $\left(N_{1}, N_{4}, N_{5}, N_{6}, N_{7}\right)$, and some were visited three times $\left(N_{2}\right.$ and $\left.N_{8}\right)$. The flexibility of visiting days that depends on the consumer's inventory status has also been validated by looking at the POR status on the DRP in each consumer. The sensitivity analysis test on the model also shows that vehicle capacity changes result in total costs and the number of routes formed. The bigger the vehicle capacity, the minimum total cost that is generated.

This research still has several possible developments that can be done, for example, by developing heuristic solutions to facilitate more consumer nodes and demand from consumers that can be varied by using several distribution patterns to get closer to the actual conditions in real life.

\section{Acknowledgments}

The researchers thank the anonymous reviewers for their helpful suggestions in this paper.

\section{References}

[1] J.-F. Cordeau, G. Laporte, M. W. P. Savelsbergh, and D. Vigo, "Chapter 6 Vehicle Routing," in Handbooks in Operations Research and Management Science. vol. 14, C. Barnhart and G. Laporte, Eds., ed: Elsevier, 2007, pp. 367-428. https://doi.org/10.1016/S0927-0507(06)14006-2.

[2] G. B. Dantzig and J. H. Ramser, "The Truck Dispatching Problem," Management Science, vol. 6, pp. 80-91, 1959. https://doi.org/10.1287/mnsc.6.1.80. 
[3] B. Eksioglu, A. V. Vural, and A. Reisman, "The vehicle routing problem: A taxonomic review," Computers \& Industrial Engineering, vol. 57, pp. 1472-1483, 2009. https://doi.org/10.1016/j.cie.2009.05.009.

[4] R. Lahyani, M. Khemakhem, and F. Semet, "Rich vehicle routing problems: From a taxonomy to a definition," European Journal of Operational Research, vol. 241, pp. 1-14, 2015. https://doi.org/10.1016/j.ejor.2014.07.048.

[5] F. Alfredo Tang Montané and R. D. Galvão, "A tabu search algorithm for the vehicle routing problem with simultaneous pick-up and delivery service," Computers \& Operations Research, vol. 33, pp. 595-619, 2006. https://doi.org/10.1016/j.cor.2004.07.009.

[6] A. Subramanian, L. M. A. Drummond, C. Bentes, L. S. Ochi, and R. Farias, "A parallel heuristic for the Vehicle Routing Problem with Simultaneous Pick-up and Delivery," Computers \& Operations Research, vol. 37, pp. 1899-1911, 2010. https://doi.org/10.1016/j.cor.2009.10.011.

[7] C. Lagos, G. Guerrero, E. Cabrera, A. Moltedo, F. Johnson, and F. Paredes, "An improved Particle Swarm Optimization Algorithm for the VRP with Simultaneous Pick-up and Delivery and Time Windows," IEEE Latin America Transactions, vol. 16, pp. 1732-1740, 2018. https://doi.org/10.1109/TLA.2018.8444393.

[8] D. Gulczynski, B. Golden, and E. Wasil, "The split delivery vehicle routing problem with minimum delivery amounts," Transportation Research Part E: Logistics and Transportation Review, vol. 46, pp. 612-626, 2010. https://doi.org/10.1016/j.tre.2009.12.007.

[9] M. Casazza, A. Ceselli, and R. Wolfler Calvo, "A branch and price approach for the Split Pick-up and Split Delivery VRP," Electronic Notes in Discrete Mathematics, vol. 69, pp. 189-196, 2018. https://doi.org/10.1016/j.endm.2018.07.025.

[10] Y. Dumas, J. Desrosiers, and F. Soumis, "The pick-up and delivery problem with time windows," European Journal of Operational Research, vol. 54, pp. 7-22, 1991. https://doi.org/10.1016/0377-2217(91)90319-Q.

[11] D. Favaretto, E. Moretti, and P. Pellegrini, "Ant colony system for a VRP with multiple time windows and multiple visits," Journal of Interdisciplinary $\begin{array}{lllll}\text { Mathematics, } & \text { vol. } & 10, & \text { pp. } & 263-284,\end{array}$ https://doi.org/10.1080/09720502.2007.10700491.

[12] P. Kirci, "On the Performance of Tabu Search Algorithm for the Vehicle Routing Problem with Time Windows," in 2016 IEEE 4th International Conference on Future Internet of Things and Cloud Workshops (FiCloudW), 2016, pp. 351-354. https://doi.org/10.1109/W-FiCloud.2016.77.

[13] D. A. P. Putri, "Vehicle Routing Problem Dengan Time Window Untuk Multiple Product Dan Multiple Route Menggunakan Algoritma Sequential Insertion," Jurnal Teknik Industri, vol. 17, pp. 22-30, 2017. https://doi.org/10.22219/JTIUMM.Vol17.No1.22-30.

[14] F. A. Gunadi, D. Lesmono, and K. Aritonang, "A Routing Model for Hybrid Huband-Spoke With Time Windows," Jurnal Teknik Industri, vol. 21, pp. 22-33, 2020. https://doi.org/10.22219/JTIUMM.Vol21.No1.22-33.

[15] R. Russell and W. Igo, "An assignment routing problem," Networks, vol. 9, pp. 1-17, 1979. https://doi.org/10.1002/net.3230090102.

[16] N. Christofides and J. E. Beasley, "The period routing problem," Networks, vol. 14, pp. 237-256, 1984. https://doi.org/10.1002/net.3230140205.

[17] M. W. Carter, J. M. Farvolden, G. Laporte, and J. Xu, "Solving An Integrated Logistics Problem Arising In Grocery Distribution," INFOR: Information Systems 
and Operational Research, vol. 34, pp. 290-306, 1996. https://doi.org/10.1080/03155986.1996.11732310.

[18] E. J. Beltrami and L. D. Bodin, "Networks and vehicle routing for municipal waste collection," Networks, vol. 4, pp. 65-94, 1974.

[19] E. Hadjiconstantinou and R. Baldacci, "A multi-depot period vehicle routing problem arising in the utilities sector," Journal of the Operational Research Society, vol. 49, pp. 1239-1248, 1998. https://doi.org/10.1057/palgrave.jors.2600641.

[20] J. Alegre, M. Laguna, and J. Pacheco, "Optimizing the periodic pick-up of raw materials for a manufacturer of auto parts," European Journal of Operational Research, vol. 179, pp. 736-746, 2007. https://doi.org/10.1016/j.ejor.2005.03.063.

[21] R. Liu, X. Xie, and T. Garaix, "Hybridization of tabu search with feasible and infeasible local searches for periodic home health care logistics," Omega, vol. 47, pp. 17-32, 2014. https://doi.org/10.1016/j.omega.2014.03.003.

[22] A. Rusdiansyah and D.-b. Tsao, "An integrated model of the periodic delivery problems for vending-machine supply chains," Journal of Food Engineering, vol. 70, pp. 421-434, 2005. https://doi.org/10.1016/j.jfoodeng.2004.05.073.

[23] E. A. Silver, "An overview of heuristic solution methods," Journal of the Operational Research Society, vol. 55, pp. 936-956, 2004. https://doi.org/10.1057/palgrave.jors.2601758.

[24] S. Pirkwieser and G. R. Raidl, "A variable neighborhood search for the periodic vehicle routing problem with time windows," in Proceedings of the 9th EU/meeting on metaheuristics for logistics and vehicle routing, Troyes, France, 2008, pp. 23-24.

[25] V. C. Hemmelmayr, K. F. Doerner, and R. F. Hartl, "A variable neighborhood search heuristic for periodic routing problems," European Journal of Operational Research, vol. 195, pp. 791-802, 2009. https://doi.org/10.1016/j.ejor.2007.08.048.

[26] P. K. Nguyen, T. G. Crainic, and M. Toulouse, "A hybrid generational genetic algorithm for the periodic vehicle routing problem with time windows," Journal of Heuristics, vol. 20, pp. 383-416, 2014. https://doi.org/10.1007/s10732-014-9244-3.

[27] R. T. Moghaddam, A. M. Zohrevand, and K. Rafiee, "Solving a New Mathematical Model for a Periodic Vehicle Routing Problem by Particle Swarm Optimization," Transportation Research Journal, vol. 2, pp. 77-87, 2012.

[28] D. Aksen, O. Kaya, F. Sibel Salman, and Ö. Tüncel, "An adaptive large neighborhood search algorithm for a selective and periodic inventory routing problem," European Journal of Operational Research, vol. 239, pp. 413-426, 2014. https://doi.org/10.1016/j.ejor.2014.05.043.

[29] L. Trihardani and O. A. Candra Dewi, "Pengembangan Algoritma Hybrid Metaheuristik Untuk Penentuan Rute Pengiriman Produk Perishable," Jurnal Teknik Industri, vol. 18, pp. 2017. https://doi.org/10.22219/JTIUMM.Vol18.No2.191-206.

[30] P. M. Francis, K. R. Smilowitz, and M. Tzur, "The period vehicle routing problem and its extensions," in The vehicle routing problem: latest advances and new challenges, ed: Springer, 2008, pp. 73-102. https://doi.org/10.1007/978-0-387-777788_4.

[31] T. Vidal, T. G. Crainic, M. Gendreau, N. Lahrichi, and W. Rei, "A Hybrid Genetic Algorithm for Multidepot and Periodic Vehicle Routing Problems," Operations Research, vol. 60, pp. 611-624, 2012. https://doi.org/10.1287/opre.1120.1048.

[32] C. Archetti, E. Fernández, and D. L. Huerta-Muñoz, "The Flexible Periodic Vehicle Routing Problem," Computers \& Operations Research, vol. 85, pp. 58-70, 2017. https://doi.org/10.1016/j.cor.2017.03.008. 
[33] R. Liu, X. Xie, V. Augusto, and C. Rodriguez, "Heuristic algorithms for a vehicle routing problem with simultaneous delivery and pick-up and time windows in home health care," European Journal of Operational Research, vol. 230, pp. 475486, 2013. https://doi.org/10.1016/j.ejor.2013.04.044.

[34] P. Francis, K. Smilowitz, and M. Tzur, "The Period Vehicle Routing Problem with Service Choice," Transportation Science, vol. 40, pp. 439-454, 2006. https://doi.org/10.1287/trsc.1050.0140.

[35] A.-K. Rothenbächer, "Branch-and-Price-and-Cut for the Periodic Vehicle Routing Problem with Flexible Schedule Structures," Transportation Science, vol. 53, pp. 850-866, 2019. https://doi.org/10.1287/trsc.2018.0855.

[36] C. Archetti, E. Fernández, and D. L. Huerta-Muñoz, "A two-phase solution algorithm for the Flexible Periodic Vehicle Routing Problem," Computers \& $\begin{array}{llllll}\text { Operations } & \text { Research, } & \text { vol. } & \text { 99, }\end{array}$ https://doi.org/10.1016/j.cor.2018.05.021.

[37] M. Darvish, C. Archetti, L. C. Coelho, and M. G. Speranza, "Flexible two-echelon location routing problem," European Journal of Operational Research, vol. 277, pp. 1124-1136, 2019. https://doi.org/10.1016/j.ejor.2019.04.002.

[38] A. Estrada-Moreno, M. Savelsbergh, A. A. Juan, and J. Panadero, "Biasedrandomized iterated local search for a multiperiod vehicle routing problem with price discounts for delivery flexibility," International Transactions in Operational Research, vol. 26, pp. 1293-1314, 2019. https://doi.org/10.1111/itor.12625.

[39] F. Theurich, A. Fischer, and G. Scheithauer, "A Branch-and-Bound Approach for a Vehicle Routing Problem with Customer Costs," EURO Journal on Computational Optimization, p. 100003, 2021. https://doi.org/10.1016/j.ejco.2020.100003.

[40] S. Poikonen, B. Golden, and E. A. Wasil, "A Branch-and-Bound Approach to the Traveling Salesman Problem with a Drone," INFORMS Journal on Computing, vol. 31, pp. 335-346, 2019. https://doi.org/10.1287/ijoc.2018.0826.

[41] Y. Ngatilah, N. Rahmawati, C. Pujiastuti, I. Porwati, and A. Y. Hutagalung, "Inventory Control System Using Distribution Requirement Planning (DRP) (Case Study : Food Company)," in Journal of Physics: Conference Series, 2020, p. 032005. https://doi.org/10.1088/1742-6596/1569/3/032005.

[42] R. Magdalena and T. Suli, "Forecasting Methods and Implementation of DRP (Distribution Requirement Planning) Methods in Determining the Master Production Schedule," IOP Conference Series: Materials Science and Engineering, vol. 528, p. 012049, 2019. https://doi.org/10.1088/1757-899X/528/1/012049.

[43] I. Rizkya, K. Syahputri, R. M. Sari, I. Siregar, M. M. Tambunan, and Anizar, "DRP: Joint Requirement Planning in Distribution Centre and Manufacturing," in IOP Conference Series: Materials Science and Engineering, 2018, p. 012243. https://doi.org/10.1088/1757-899X/434/1/012243.

[44] A. Saltelli, "Sensitivity Analysis for Importance Assessment," Risk Analysis, vol. 22, pp. 579-590, 2002. https://doi.org/10.1111/0272-4332.00040. 